\title{
CONSTRUCCIÓN DEL VERSO MODERNO
}

\author{
José Domínguez CAPARRós
}

¿Qué es el verso moderno? ¿A qué época pertenece exactamente? ¿Qué características tiene el verso moderno, entendido, lógicamente, como los versos modernos? Dice Navarro Tomás (1973: 183), al principio de su trabajo sobre Gertrudis Gómez de Avellaneda:

Nombres preeminentes por su representación innovadora en la larga historia de la versificación española son los de Gonzalo de Berceo, maestro de la cuaderna vía; Juan de Mena, principal artífice del verso de arte mayor; Boscán y Garcilaso, adaptadores del endecasílabo italiano, y Rubén Darío, indiscutible definidor de los ritmos modernistas.

En la lista de grandes nombres de la historia del verso, el moderno debe asociarse, pues, a Rubén Darío (1867-1916). Coincidiríamos, así, con la observación de Dámaso Alonso (1952: 549), cuando sitúa en 1896 (publicación de Prosas profanas) el comienzo del segundo período áureo de la poesía española. El primero es el que empieza en 1526 (conversación en Granada) con la decisión de cultivar los metros endecasilábicos. A fines del siglo xIx, los nuevos poetas de América, con Rubén Darío a la cabeza, atacan, según P. Henríquez Ureña (1961: 17), la teoría del verso silábico y acentual, cuando «se lanzaron a ensayar toda especie de formas métricas desusadas, hasta llegar al moderno verso libre». ${ }^{1}$

El cambio más vistoso que sufre la versificación culta a fines

1 Tampoco tiene dudas Regino E. Boti (1921: 365-366) sobre el mayor peso de la poesía americana en la renovación del verso moderno. 
del siglo xix es la canonización de formas de verso irregular que Pedro Henríquez Ureña (1961: 249-250) concreta en la restauración del "amétrico" y el "acentual”, y en los nuevos ensayos de la versificación de pies silábicos y de versificación cuantitativa. Explica que el impulso de la uniformidad isosilábica durará hasta 1895 (1961: 213).

Habría que completar el carácter de la moderna versificación diciendo que también el verso silábico tradicional amplía el repertorio de sus formas. Muy frecuentemente hace esto con el ensayo de nuevas combinaciones acentuales que llevan a explorar las posibilidades silabotónicas del verso español. Ensayos que hay que considerar claros precedentes de la versificación moderna de cláusulas, que P. Henríquez Ureña no duda en calificar como forma de métrica irregular. ${ }^{2}$

Desde la amplia perspectiva que proporciona el panorama de una historia de la versificación europea, M. L. Gasparov hace observaciones que caracterizan muy bien el verso culto español, teniendo en cuenta las pocas páginas que forzosamente puede consagrar a nuestra métrica en un campo tan grande de estudio. Esto tiene la ventaja de que debe ir a lo verdaderamente esencial dentro de contexto tan ancho; y lo fundamental es que hasta fines del siglo xix los metros dominantes son el octosílabo (forma corta) y el endecasílabo (forma larga con un «rudimentary sylla-

${ }^{2}$ P. Henríquez Ureña, al no ver la versificación de cláusulas sobre el fondo de un ritmo silabotónico general del verso regular, destaca solamente la ametría (relativa, diríamos nosotros) y por eso la asocia a la versificación libre, la esencialmente amétrica. En definitiva, lo que no considera P. H. U. es el carácter silabotónico del verso español, pues le interesa más estudiar su objeto (la versificación irregular) exclusivamente a partir del número de sílabas. Ya en 1905, en su trabajo sobre Rubén Darío, incluye el Nocturno de José Asunción Silva y la Marcha triunfal de Rubén Darío en los ejemplos de verso libre sujeto a un "ritmo más o menos fijo" (P. Henríquez, 1905: 213). Sin embargo, el desarrollo del silabotonismo en nuevas formas de verso silábico -desarrollo que se da ya en el neoclasicismo (Iriarte) y en el romanticismo- tiene una expresión final en la versificación de cláusulas. De hecho, el análisis silabotónico es empleado (en la misma forma en que luego se empleará en la versificación de cláusulas) por Andrés Bello para estudiar toda la versificación. En la discusión entre E. de la Barra y E. Benot sobre el nuevo tipo de versificación subyace como una de las cuestiones importantes, la de si el verso de cláusulas es invento nuevo o existe de antes (Véase J. Domínguez Caparrós, 1975: 101-105). 
botonic, iambic, rhythm»; los demás metros constituyen «a metrical periphery» (1996: 137-140). Tendríamos aquí enunciado lo que sería la nota más destacable de la versificación española desde el siglo XVI hasta fines del XIX. ${ }^{3}$

El resumen del recuento de la versificación de todas las obras de Cervantes aporta datos que confirman totalmente la observación de Gasparov. En efecto, de un total de 42.046, son octosílabos 23.377, endecasílabos 16.656, y heptasílabos 1.454; el resto de los versos, en los que hay que incluir principalmente hexasílabos, 96 versos de arte mayor, y versos de estribillos y cantares, suman sólo 559 (Domínguez Caparrós, 2002: 60). ${ }^{4}$

Para hacernos una idea más concreta de cuál es la métrica de la poesía culta moderna, es decir, de cuáles son las formas de los versos modernos, mencionemos algunas de las más llamativas. Pedro Henríquez Ureña (1961: 236-242), que sitúa en Prosas profanas el resurgimiento de la versificación irregular en la poesía culta, nos puede servir de guía, cuando hace la relación de metros que «adquieren nuevo brillo» en la mencionada obra: el doble octonario, en "Año nuevo" (1894); alejandrino; eneasílabo, combinado con el alejandrino, en "Responso a Verlaine" (1896); decasílabo (anapéstico y bipartito); dodecasílabo (anfibráquico y de seguidilla); endecasílabo, en todas sus variedades, entre las que son dignas de destacar la acentuada sólo en $4^{\mathrm{a}}$ y la acentuada en $4^{\mathrm{a}}$ y $7^{\mathrm{a}}$. Entre los poemas de versificación irregular cita: Canto de la sangre (1894), La página blanca (1896), Dice mía (¿1895-6?), Heraldos; y el ensayo de prosa rítmica de El país del sol (1893). En Cantos de vida y esperanza (1905) destaca el verso cuantitativo a la manera clásica de la "Salutación del Optimista" (1905), que «sugiere de modo vago el rumor del

3 El carácter silabotónico latente del verso español ha estado presente en las observaciones de los tratadistas españoles sobre el endecasílabo siempre. J. Coll y Vehí, por ejemplo, dirá que es «el verso más artificioso, el que más importancia concede al ritmo de acento», por eso es «el único que puede andar con paso firme y seguro sin la muleta del asonante o del consonante» (1866: 248-9). Rengifo (1606: 14-15) hablaba de ocho maneras de acentuarlo y que «son las que hazen el verso más corriente, grave, y sonoro».

4 Pedro Henríquez Ureña (1905: 211) dice que antes de Rubén Darío, «los más de nuestro idioma, [fueron] poetas de endecasílabo y de octosílabo». 
hexámetro» -verso que también empleará en la "Salutación al águila” (1906), de El canto errante (1907)-; la versificación fundada en un pie acentual (o ó o), como en la "Marcha triunfal" (1895); ensayos de verso libre, no en forma amétrica, sino con fluctuación alrededor de un paradigma, como el de la silva italiana -así, en la segunda parte, vv. 21-35, de «Divina psiquis...»-, con adición de alejandrinos y eneasílabos en «Oh, miseria de toda lucha...»; o como el de los ritmos octosilábicos -versos de 12, 8, 6 y 10 sílabas en “¡Aleluya!”-; y ensayos claramente libres como el de "Augurios". Versificación libre moderna que se manifestará en todo su esplendor en los 1001 versos del "Canto a la Argentina”, 1910.

Podríamos remitir igualmente a la lista de 37 formas de metros registradas por Tomás Navarro Tomás (1973: 220-221) en la poesía de Rubén Darío.

Está claro que si vamos a tomar el verso rubeniano como punto de partida y símbolo del verso moderno español, hay que considerar una historia de preparación del mismo, de innovaciones, renovaciones o nuevos planteamientos que abocarán en el verso asociado a la poesía del nicaragüense. El principio de tal historia, en sus aspectos teóricos y prácticos, debe situarse en el siglo XVIII, siglo de arranque de la modernidad también en la métrica. El nombre de Tomás de Iriarte (1750-1791) tiene que asociarse al comienzo de la práctica del verso moderno. El de la segunda edición de la Poética de Luzán (1789), y, sobre todo, el de Juan Francisco de Masdeu (1801), al de la teoría moderna. ${ }^{5}$

En las conclusiones de su trabajo sobre la versificación de Iriarte, D. C. Clarke (1952: 419) ha señalado las aportaciones del poeta canario a la métrica, para terminar diciendo que si vemos

that all the rhythmic patterns tried by Iriarte flourished vigorously, we can surely say that Iriarte's pioneering had some part in

${ }^{5}$ Ejemplo elocuente del cambio de actitud de Luzán son las adiciones que en 1789 hace al capítulo XXII del libro II. Como muestra, obsérvese la cita de versos de Berceo o Gil Polo para el de catorce sílabas; de Jerónimo de Villegas, para el verso de arte mayor; o eneasílabos (Luzán, 1977: 360-361). Coll y Vehí (1866: 109) destaca el valor de ruptura que tiene la teoría de Masdeu, quien «se limitó a demostrar, y con sumo acierto, la verdadera influencia del acento en el verso castellano, haciendo caso omiso de la teoría del verso castellano a imitación del latino». 
preparing a foundation for modern metrical practice.

La observación de Pedro Henríquez Ureña (1961: 210-211), hecha desde el punto de vista de la historia de la versificación irregular, apoya nítidamente el comienzo de la constitución del verso moderno a fines del siglo XVIII:

Hacia el final del siglo xviII, la antigua versificación irregular ha desaparecido a tal punto de la literatura, que ni siquiera sus reliquias parecen peligrosas a los clasicistas académicos, y se comienzan a exhumar versos desusados, como el endecasílabo de gaita gallega o el eneasílabo o el dodecasílabo o el decasílabo bipartito, para emplearlos en combinaciones isosilábicas e isométricas.

Encontramos en estas palabras un buen índice de nuevas formas del verso isosilábico. Y, por supuesto, no falta la mención de Iriarte y de Leandro F. de Moratín. ${ }^{6}$

En una de las notas de su Espagne poétique (1826), el buen conocedor de la versificación que fue Juan María Maury nos da un testimonio precioso acerca de la apertura del canon en su tiempo y del lugar que en dicho proceso ocupa Iriarte: la poética española, dice, «donne, pour ainsi dire, carte blanche aux versificateurs: elle admettra toutes les mesures dont il saura tirer parti». Y en nota explicativa de esta afirmación, dice que aprovecha esta facultad el elegante autor de nuestras fábulas literarias, D. Tomás de Iriarte: «il a joint à la différence des mesures différentes symetries entre elles et les rimes, et il fait remarquer quarante combinaisons» (1826: 23). ${ }^{7}$

El soberbio monumento de la historia de la métrica española construido por Tomás Navarro Tomás (1956) da cuenta de la

${ }^{\mathbf{6}}$ En su trabajo sobre la métrica de los poetas mexicanos en la época de la independencia, dice P. Henríquez Ureña: «D. Tomás de Iriarte y D. Leandro Fernández de Moratín habían ensayado nuevas combinaciones métricas, que no se aprovecharon en el romanticismo, sino más bien hoy, en el modernismo iniciado en América» (1961: 362).

${ }^{7}$ Es el mismo Iriarte quien advierte de la diversidad de formas empleadas: «[...] para llamar la atención de los jóvenes que los lean, y se inclinen al arte métrica castellana, se ha añadido al fin de la obra un breve índice de los cuarenta géneros de metro en que está compuesta, empezando por los de catorce sílabas y acabando por los 
riqueza de las formas del verso español desde la segunda mitad del siglo XVIII hasta Rubén Darío. ${ }^{8}$ La interesante, original y no escasa producción de teoría métrica, sobre todo en el siglo XIX, ha sido presentada en el panorama general que tracé yo mismo en 1975. Una ojeada, por ejemplo, al diccionario de testimonios sobre formas métricas que va al final de mi estudio bastará para demostrar la novedad y variedad adquiridas por el verso español en este período.

El comentario que intento a continuación debe ser forzosamente limitado. Primero, porque se centra en la estructura del verso, prescindiendo de los esquemas métricos de estrofas o características del empleo de la rima, por ejemplo. Segundo, porque tampoco es posible una descripción y comentario de las muchas formas adoptadas por cada uno de los versos. Trataré, pues, de aislar unas características generales de la teoría y la práctica del verso español desde fines del siglo XVIII a fines del siglo XIX, para ver cómo se va preparando la constitución del verso moderno.

Cuatro son las notas que me parecen dignas de destacar: primero, la irrupción de un sentido histórico en las consideraciones métricas; segundo, la importancia del análisis de la estructura interna del verso; tercero, la ampliación de los límites silábicos del verso tradicional; y cuarto, la indagación en las posibilidades del silabotonismo. Comento y ejemplifico brevemente cada una de estas notas.

de cuatro» (1963: 4). La lista confeccionada por el mismo autor puede leerse en págs. 90-91; y un comentario del editor, Alberto Navarro González, en págs. L-LIII del prólogo al volumen 136 de Clásicos Castellanos, que contiene las poesías de Iriarte.

8 Andrés Bello decía: «No hai lengua moderna en que los accidentes métricos sean capaces de tanta variedad de combinaciones» (apud J. A. Dreps, 1939: 35). 
Ignacio de Luzán (1789), Luis Joseph Velázquez (Orígenes de la poesía castellana, 1754; 1797, $2^{\mathrm{a}}$ ed.), el P. Martín Sarmiento (Memorias para la historia de la poesía y poetas españoles, 1775), o Tomás Antonio Sánchez (Colección de poesías castellanas anteriores al siglo XV, 4 vols., 1779-1790) demuestran un interés por las formas pasadas de la métrica castellana. Es muy llamativa la mayor presencia de noticias históricas en la segunda edición de la Poética (1789) de Luzán. Así, por ejemplo, en el capítulo nuevo sobre la rima (el XXIII), al tratar del verso suelto (el que no tiene rima ni asonante), se pregunta por lo que hubiera sido el verso endecasílabo si en el tiempo en que se introdujo en la poesía moderna la rima no hubiera tenido la importancia que tenía. Piensa Luzán (1977: 371) que

acaso los tendríamos ahora con toda la libertad y variedad en la frase, en la situación de acentos, en las transposiciones, en el pasaje de unos versos a otros, en las pausas y suspensiones y, en una palabra, con toda la perfección de que yo los juzgo susceptibles.

Las características del verso son hijas de las circunstancias de su tiempo y susceptibles, por tanto, de modificación. ${ }^{9}$ Igual sentido histórico puede apreciarse en el capítulo XXIV, "Del buen uso de la rima”, pues no hay que olvidar que es la experiencia y la crítica las que proporcionan las reglas y observaciones necesarias a quienes quieren perfeccionar sus obras (1977: 375).

No hay duda de que el sentido histórico es factor esencial de fomento de un sano relativismo que influye en las circunstacias propicias para la innovación y la discusión. La métrica entra en el campo de la historia, que explicará y relativizará el significa-

${ }^{9}$ El mismo sentido histórico se manifiesta en este capítulo cuando trata del asonante y su origen. Por cierto que Luzán comenta muy bien cómo casi todos los romances del Cancionero general tienen rima consonante, lo mismo que en los de casi todos los poetas que vivieron hasta principios del reinado de Felipe II (1977: 368). 
do del uso de las distintas formas de versificación.

Dos ejemplos nada más como índice de la normal presencia del sentido histórico en el pensamiento métrico del siglo XIX. Cuando Miguel Agustín Príncipe ejemplifica el bisílabo con versos de Zorrilla, en Un testigo de bronce, habla de

su sistema de variar los metros según su capricho le dicta; moda que se generalizó entre nosotros cuando nos invadió completamente la calentura del romanticismo. La escuela conocida con este nombre nos ha traído, a decir verdad, un gran número de cosas buenas, mas también nos las trajo muy malas, entre ellas una más que mediana perversión en ciertas ideas, un desdén injustificable en lo que hace relación a ciertas formas, y una muy regular anarquía en materia de versificación (1861-2: 496).

A los ensayos románticos aluden, sin duda, también las siguientes palabras de José Coll y Vehí, que constituyen el segundo ejemplo. Dice en sus Elementos de Literatura (1856; 1857, $2^{\mathrm{a}}$ ed.: 204-205):

Algunos poetas contemporáneos, esforzándose en dar variedad y novedad al metro, han atendido más a la parte puramente musical que a la verdad y energía de la expresión. Otros, llevados de un necio empeño en apartarse de las formas clásicas y aspirando a una imitación, pueril, imposible y viciosa en la música, y más defectuosa e imposible todavía en la versificación, han reunido los metros más opuestos y caprichosos en un mismo poema, convirtiendo la poesía en lo que los franceses llaman con toda propiedad un tour de force.

El sentido histórico se conjuga muy bien con la ampliación de formas silábicas o la indagación en estructuras silabotónicas que luego comentaremos. Antes veamos algo que tiene que ver con la tendencia de la teoría métrica del momento: su preocupación por profundizar en el descubrimiento de la estructura interna del verso. 
Habla M. L. Gasparov de un complejo de inferioridad de las formas de verso silábico europeo respecto del verso clásico, que se veía mucho mejor organizado. Por eso se trataba de guardar cualquier reliquia que recordara, en la terminología al menos, un origen en los “pies” clásicos (Gasparov, 1996: 143). El prestigio del modelo clásico grecolatino de los pies métricos está atestiguado en la métrica española desde Nebrija (Díez Echarri, 1970: 153-158). Pero, aunque todavía en Luzán pesa el ejemplo del verso clásico latino, es muy destacable el cambio radical que se produce en el siglo xix: el análisis de la estructura del verso se basa en el acento exclusivamente; y si en algún caso, como ocurre en Bello, conserva parte de la terminología de la métrica latina, el sentido de dichos términos está despojado de un significado relacionado con la cantidad, pues sólo se considera el número de sílabas y el lugar del acento. Como es sabido (Domínguez Caparrós, 1975: 83-111), Masdeu (1801), Sinibaldo de Mas (1832), Bello (1835) -seguido por E. de la Barra y por E. Benot- y Miguel Agustín Príncipe (1861-2) proponen distintas formas de análisis de la estructura del verso.

Los versitos conforman los versos compuestos -son compuestos todos los versos que tienen más de tres sílabas- de Masdeu [«Temor / en este pecho / no reside»]. La colocación de los acentos en el verso conforma, en el sistema de Sinibaldo de Mas, lo que llama $1^{\mathrm{a}}, 2^{\mathrm{a}}, 3^{\mathrm{a}} \ldots$ para designar el lugar de la sílaba acentuada contando desde el principio del verso o desde el acento anterior [ «El dúlce lamentár de dos pastóres»: $2^{\mathrm{a}}, 4^{\mathrm{a}}$, $4^{\mathrm{a}}$ ]. La cláusula rítmica de Bello designa cada una de las partes que resultan de dividir el verso en grupos iguales de dos o tres sílabas con el acento en el mismo lugar del grupo, lo que da la lista de cinco clases distintas de cláusulas. Los grupos silábicos ( «o como deban denominarse») de Miguel Agustín Príncipe, que dan una idea aproximada de lo que eran los pies o metros de los antiguos, se constituyen a partir de un acento y las sílabas átonas 
que siguen hasta el acento siguiente (que es el principio de otro grupo): «Nóchecrü / èl me / cércapavo / ròsa». Hay que destacar la similitud de este modo de dividir con el de Tomás Navarro Tomás.

Sistemas como los mencionados no sólo sirven para analizar la estructura de todos los versos, sino que serán uno de los caminos por los que se propondrán nuevos tipos de versos castellanos, como ilustran muy bien Sinibaldo de Mas y Eduardo de la Barra. ${ }^{10}$ Del interés que tiene la lectura de estos tratados para la teoría moderna del verso, sólo voy a dar el ejemplo de Masdeu cuando considera como última de las tres formas de endecasílabo la que describe como resultado de la unión de

tres versos menores; el primero de cinco pies [sílabas]; y los otros dos de tres pies cada uno.

Sále la Auróra $=$ con rúbios $=$ cabéllos,

1.2. 3. 4.5. 1. 2. 3. 1. 2. 3 .

Dándo a las flores $=$ colóres $=$ muy béllos.
1. 2.
3. 4. 5 .
1. 2. 3.
1. 2. 3 .

Se trata del raro endecasílabo dactílico (también llamado anapéstico), que se confunde con el de gaita gallega. Pero lo curioso es lo acertado de su vinculación con una de las formas del italiano, cuando dice:

10 Hasta en un verso tan regularizado en el uso y en la teoría como el endecasílabo señala Eduardo de la Barra posibilidades de innovación: «Lo dicho hace ver que pueden componerse nuevos endecasílabos fuera de los conocidos, dáctilo y yambo, de dos maneras: o juntando dos versos, o combinando cláusulas rítmicas de modo que sumen once sílabas y agraden al oído» (1891: 58). Sólo por un afán de resaltar las innovaciones modernistas se explica que Max Henríquez Ureña, en sus Estudios de versificación (1913) afirme que los preceptistas del xIX (entre los que cita a Hermosilla, Arpa y López, Gil y Zárate, Coll y Vehí, Campillo) ignoran el secreto del ritmo, «desconocían la estructura íntima del verso» (1913: 91). En lo que respecta a Coll y Vehí, esto no es exacto; y, por supuesto, lo sería menos si hubiera mencionado a Bello. Para Max Henríquez: «La versificación tiene una estructura íntima que está sometida a fórmulas mecánicas y precisas, como lo está la música» (1991: 92). Destaca a Eduardo de la Barra como primer tratadista que intenta comprender el verso, al principio del modernismo. Tampoco resulta ocioso recordar que Masdeu (1801: 52) considera la «armonía intrínseca» del verso en función del número de sílabas y la disposición de los acentos. 
aunque muy del gusto de Dante, y de otros poetas antiguos; ya no se usa hoy día, sino en ciertos cantares proprios de marineros, en cuyo estilo han escrito algunos italianos elegantemente (1801: 73-74).

Elemento esencial de la estructura del verso es también la pausa, que en este período es objeto especial de discusión y análisis también. Con recordar a A. Bello y sus propuestas definitivas sobre el asunto, queda probada la atención que en este momento despierta el estudio del interior del verso. Cómpletese el esfuerzo de definición con las muchas observaciones acerca del mejor lugar de estos descansos en el interior del verso, sobre todo en los versos largos. En este sentido, el endecasílabo es objeto privilegiado de análisis. Sarmiento o Jovellanos, Maury o Bello, Lista o Coll y Vehí, entre otros muchos, pueden ofrecernos ejemplos de esta atención al lugar de los descansos en el interior del verso, por no hablar de la atención prestada al encabalgamiento (J. Domínguez Caparrós, 1975: 237-294, 424429).

El sentido y la importancia de los análisis de la estructura interna quedarán más claros cuando digamos algo más del silabotonismo. Pero antes conviene referirse a la ampliación de los límites silábicos del verso.

Fundamentalmente se trata del ensayo de nuevas clases de verso silábico. Como punto de partida, para percibir las nuevas formas, podemos tomar la lista de tipos de verso que se establece en el libro clásico de Rengifo (1606: 12):

Ay nueue maneras de versos. De Redondilla mayor, y su quebrado: de Redondilla menor: Italiano, y su quebrado: Esdrúxulo, y su quebrado: de Arte mayor: finalmente verso Latino imitado. 
Es decir, hay versos de ocho y de cuatro sílabas; de once y de siete; de once y de siete esdrújulos; de arte mayor, que Rengifo considera silábico, con acento en la segunda y quinta de cada uno de los dos hemistiquios hexasílabos; imitación del verso latino. ${ }^{11}$

En mi trabajo sobre historia de las teorías métricas (Domínguez Caparrós, 1975: 222-233) expuse los datos más destacables que explican cómo la lista de clases de versos silábicos no es única en los siglos XVIII y xix. Sólo quiero subrayar, como novedad más importante respecto de Rengifo, la temprana presencia del verso de catorce sílabas o alejandrino en las propuestas de los tratadistas. Visto desde una perspectiva amplia, el silabismo de la métrica española se distingue, en su época posmodernista y contemporánea, por la integración y protagonismo del alejandrino, muchas veces mezclado con los ritmos endecasilábicos, que incluyen el heptasílabo. ${ }^{12}$

El establecimiento de la lista completa de los tipos del verso moderno es una tarea muy dificultosa. La mejor referencia sigue

11 Aunque el adicionador de Rengifo en el siglo XVIII, Joseph Vicens (1759: 15), da cabida en su lista a tres géneros de quebrados (de cinco, de tres y de dos sílabas) y a versos de nueve y de diez sílabas. Pero se trata, en el caso de los quebrados, de versos que «usan los más célebres Poetas, ya en las Seguidillas, ya en los Villancicos; como en otras Poesías, conformándose con la Música, que así requiere a veces los sobredichos Quebrados». En cuanto a los eneasílabos y decasílabos, se refiere a los del estribillo del villancico, de que trata en el capítulo 41. Parece que Vicens está pensando en formas de versos que aparecen en manifestaciones musicales casi siempre irregulares. Por eso no puede pensarse en una ampliación de la versificación silábica a principios del siglo xviII. Más bien habría que decir lo contrario, si tenemos en cuenta que P. Henríquez Ureña (1961: 207-9) habla precisamente de una transformación, "por influjo de los hábitos literarios», de los metros irregulares en la poesía culta entre 1675 y 1725. Por ejemplo, la seguidilla fija su forma en la alternancia de heptasílabo y pentasílabo; la gaita gallega se reduce a la combinación deca-dodecasilábica, con posibilidad de algún quebrado hexasílabo y a veces endecasílabo anapéstico.

Habría que pensar, entonces, que el siglo XvIII empieza con una regularización, por influjo de la literatura culta, pero, al mismo tiempo, habría que pensar también que esta regularización pudo influir, con sus nuevos ejemplos de versos, en la búsqueda de nuevos ritmos en el verso silábico.

12 Combinaciones muchas veces perceptibles en el verso libre moderno. Véase, entre los no escasos ejemplos de la poesía contemporánea, un libro como Variaciones sobre un tema de La Bruyère (1974), de Guillermo Carnero. 
siendo la de Tomás Navarro Tomás (1956), pero no hay duda de que todavía quedan parcelas por investigar y datos por sistematizar. Una de las dificultades mayores del estableciemiento del canon $^{13}$ métrico del verso español es el del paso de una forma que se origina o vive en el extrarradio al reconocimiento oficial. Pues aquí se plantea el problema de historia literaria de la relación entre corrientes oficiales y otras no reconocidas como tales, o la cuestión de géneros altos y otros considerados menores. Si se fija previamente el canon de poetas y obras en el que se tiene que basar el establecimiento de las formas métricas canónicas, se dejarán al margen muchos datos sin duda interesantes para la historia de la versificación. Recuérdense las palabras de Rubén Darío en su prefacio a Cantos de vida y esperanza (1905):

En cuanto al verso libre moderno..., ¿no es verdaderamente singular que en esta tierra de Quevedos y Góngoras los únicos innovadores del instrumento lírico, los únicos libertadores del ritmo, hayan sido los poetas del Madrid Cómico y los libretistas del género chico?

Otro ejemplo. El ovillejo, que en la historia canónica de la poesía va de su inventor, Cervantes, a Sor Juana Inés y luego al Don Juan Tenorio de Zorrilla, conoce otros episodios intermedios. Esta historia menos conocida explica cómo de las derivaciones barrocas de Sor Juana se pasa a una recuperación de la forma cervantina originaria en poesía no canónica de propaganda política en el siglo xIX, y es un juego al que no renuncia Rubén Darío -aunque se trate de muestras no recogidas en sus libros de poesía- y que aún sigue vivo en la poesía porteña argentina (Domínguez Caparrós, 2002: 147-151).

Hay que estar de acuerdo una vez más con Pedro Henríquez Ureña (1961: 18) cuando dice:

13 El empleo del concepto de canon en métrica no data de la moderna discusión general sobre el canon en teoría literaria. Ya en 1913, en su estudio sobre la Avellaneda, R. E. Boti (1913: 387) habla de su rebelión «contra lo trillado del canon» para comentar las innovaciones de la cubana en la décima espinela. También Pedro Henríquez Ureña (1961: 213) se refiere al «canon isosilábico». 
El estudio de la versificación castellana es mucho menos sencillo de lo que hasta hace poco parecía.

Pueden trazarse, pues, dos historias de la métrica: una primera sería la de registro y recuento estadístico de todas las manifestaciones del verso en todos los géneros. El enunciado de tal proyecto da una idea de la casi imposibilidad de acabar una tarea semejante, aunque deba hacerse en parcelas concretas (por épocas, géneros, autores, formas determinadas); y de que la magnífica guía de T. Navarro Tomás no ha agotado el campo de la investigación métrica. La otra historia sería la que se pliega a la historia de la poética y analiza la versificación de las obras que han pasado la prueba del tiempo y perduran en el canon de modelos literarios. Por supuesto que esta distinción teórica no prohíbe el trasvase de datos de un tipo a otro de investigación.

Por lo que se refiere al período que nos ocupa, el de la construcción premodernista del verso, parece que las innovaciones de Tomás de Iriarte, por ejemplo, sin la consagración posterior de los poetas más representativos, no hubieran pasado de simples curiosidades. Hay ensayos de poetas que no aparecen en las historias de la literatura canónicas y que sin embargo son muy innovadores en las formas métricas. ¿Hasta qué punto influyeron o son nada más que un síntoma que anuncia los nuevos tiempos? El caso del malagueño Juan María Maury (1772-1845), por ejemplo, no deja de llamarnos la atención. Su composición El festín de Alejandro. Oda en ritmo ditirámbico, traducción de un poema del inglés J. Dryden (1631-1700), es sorprendente desde el punto de vista métrico. ${ }^{14}$ Los cinco últimos versos son citados por Pedro Henríquez Ureña (1961: 212) como ejemplo del desorden de -combinaciones medianamente libres- que a 14 Publicado por Leopoldo Augusto de Cueto en el vol. 67 de la BAE, págs. 173-174, el poema consta de 141 versos, que van de las 3 a las 14 sílabas, pero no hay de 13 sílabas. Tiene rima consonante; sólo 4 versos quedan sueltos, de los que dos son esdrújulos (14 y 17), y dos terminan en eco (68: hunden, hunden; y 94: mera, quimera). Ninguna estrofa repite esquema, y en los versos hay un ritmo acentual muy marcado: eneasílabo (yámbico y anfibráquico), dodecasílabo anfibráquico, octosílabo trocaico, alejandrino yámbico, decasílabo anapéstico, heptasílabo yámbico, endecasílabo yámbico. 
veces aparecen en óperas, cantatas y otras creaciones cortesanas a principios del siglo Xıx. ${ }^{15}$

Poetas consagrados que interesan para el proceso de construcción del verso moderno son Espronceda, Zorrilla, Bécquer, Rosalía de Castro y Rubén. Puede haber una línea de poetas menos influyentes, en la que estaría, por ejemplo, Gertrudis Gómez de Avellaneda, pero de gran interés para la historia de la métrica. Una vez más, T. Navarro Tomás nos da pistas útiles para comprender el significado de algunos de estos poetas en el proceso de construcción del verso moderno, cuando dice:

Los poetas románticos de lengua española más señalados por la variedad de su métrica fueron Espronceda, Zorrilla, Echeverría y la Avellaneda (1973: 198).

Pero casi interesa más el lugar donde sitúa su originalidad: en la atención a «los efectos del ritmo y sonoridad del verso», más que en «la variedad de sus combinaciones estróficas». Y una nota que apoya la tesis que venimos defendiendo es que en esto se diferencia de la versificación del siglo de oro, que es «más rica en estrofas que en metros».

El afán por desentrañar los principios de la estructura interna del verso y proponer nuevas formas tiene su máximo representante en Sinibaldo de Mas. Entre sus innovaciones, como recoge Navarro Tomás, ${ }^{16}$ se encuentran ejemplos únicos, o la primera manifestación de versos luego empleados en el modernismo. Es ésta una actitud que se desarrollará más adelante entre los tratadistas relacionados con el modernismo, empezando por

${ }^{\mathbf{1 5}}$ Hay que señalar que los cinco últimos versos, a que se refiere Henríquez Ureña, tienen un marcado ritmo acentual: ternario en los dodecasílabos (acento en $2^{\mathrm{a}}$ y $5^{\mathrm{a}}$ de cada hemistiquio) y decasílabos (acento en $3^{\mathrm{a}}, 6{ }^{\mathrm{a}}$ y $9 .^{\mathrm{a}}$ ); binario en el último verso, que puede leerse como alejandrino $(7+7)$ que acentúa las sílabas 2. ${ }^{\mathrm{a}}, 4$. $^{\mathrm{a}}$ y 6 . $^{\mathrm{a}}$ de cada hemistiquio, o como tridecasílabo que acentúa todas las sílabas pares, si se hace sinalefa entre los hemistiquios: Y, a fuer de nueva Helena, incendia nueva Troya. Está claro que Henríquez Ureña está pensando exclusivamente en el número de sílabas, como cuando trata la versificación de cláusulas, si aplica el calificativo de «medianamente libres» a estos versos, sometidos a un ritmo acentual tan estricto. conoció su Sistema musical de la lengua castellana entre 1832 y 1852. 
Eduardo de la Barra, pero también Eduardo Benot. Y ya en el siglo xx, Ricardo Jaimes Freyre (1912), Max Henríquez Ureña (1913), Pérez y Curis (1913) dan testimonio en sus tratados de la efervescencia teórica que indaga formas de distintos ritmos en el verso. ${ }^{17}$ Algo más tarde, Julio Vicuña Cifuentes (1929) o los estudios de Julio Saavedra Molina representan muy bien el interés por el análisis de los secretos del ritmo del verso moderno. Es Hispanoamérica quien tiene la ventaja sobre España en el terreno de la reflexión sobre el verso.

Pero más que entrar ni siquiera en el índice de las muchas formas que puede presentar el verso desde las dos a las dieciséis sílabas, o la mezcla de versos de distintas medidas, me gustaría examinar las respuestas de algunos autores de este momento a la pregunta esencial sobre los límites y condiciones de la existencia de formas tan variadas de verso.

Luzán plantea la cuestión, la pregunta esencial, de por qué once, siete u ocho sílabas forman verso, y no lo forman el conjunto de doce, trece, quince o diecisiete. La intención de Luzán es la de demostrar que el verso no depende sólo del número de sílabas, sino también de la cantidad, como en los clásicos, aunque en español la apariencia de cantidad depende del acento (Luzán, 1977: 347-348). Lo que supone lo mismo que decir que el acento es fundamental en el verso. Ahora bien, a esta pregunta de Luzán se le dio, en los ecos que tiene en tratadistas posteriores,

${ }^{17}$ Un ejemplo típico que merece la pena mencionar por ser poco conocido es el de la propuesta de Luis Llorens Torres, director de la Revista de las Antillas, en cuyo número cuatro, de junio de 1913, publica su teoría, comentada por Max Henríquez Ureña en sus Estudios de versificación (1913: 93-103). Fundamentalmente se trata de basar el ritmo del lenguaje -tanto de la prosa como del verso- en la combinación de versos puros (los de dos y tres sílabas). Las posibilidades de combinación dan la clave de todas las clases posibles de versos. Si la combinación es simétrica tenemos verso; si se rompe la simetría, prosa. Así, por ejemplo, en el caso del endecasílabo, son nueve las combinaciones posibles. Algunas responden a tipos conocidos de endecasílabo, pero hay otros cuatro que son desconocidos, y que llevan acento en: $1,3,5,8$ y 10; 1, 3, 5, 7 y 10 -para este tipo el autor escribe un soneto, titulado “Germinal”, que reproduce Max Henríquez-; 2, 5, 7, y 10; 2, 5, 8 y 10. Como vemos, no hay reparos en ensayar continuamente nuevas formas de versos. La crítica a que M. Henríquez somete esta propuesta es un magnífico ejemplo de la efervescencia teórica del modernismo. 
un sentido más general y centrado en la cuestión de los tipos de versos y los márgenes silábicos aceptados o aceptables. En este sentido, Juan Gualberto González (1844, III: 31 y 34) responde a Luzán diciendo que

la armonía de los versos depende de la costumbre. El que por la vez primera oyese recitar un verso de cualquier género, me parece a mí que no encontraría en él cadencia alguna particular, que no encontrase en cualquier período de los que tenemos por sonoros en la prosa.

Por eso, si los versos de trece sílabas «fueran más usados», y el oído estuviera acostumbrado a ellos como lo está al endecasílabo, «los hallaría igualmente armoniosos», pues, para J. G. González los límites del verso están entre las cuatro y las catorce sílabas.

Sinibaldo de Mas, tras la descripción de los metros fundados en el acento prosódico -metros de siete a catorce sílabas-, cita las palabras de Luzán en apoyo de su tesis de que cualquier número de sílabas vale para hacer uno o varios tipos de verso:

Estos ejemplos bastarán, me figuro, para hacer ver que con cualquier número de sílabas dado se puede hacer un verso, y no solamente uno, sino dos, tres o más diferentes (2001: 92).

Esto le da la posibilidad de proponer hasta 24 tipos de tridecasílabo, y aun a pensar en combinaciones de endecasílabo con nuevas cadencias. Como ejemplo, el acentuado en 4, 7 y 10 del poema La Aurora, cuya originalidad ha sido destacada por Navarro Tomás, y que ha sido puesto en relación con los versos de Pórtico, de Rubén Darío, que van al frente del libro de Salvador Rueda, En tropel (Sinibaldo de Mas, 2001: 94-95).

Miguel Agustín Príncipe limita el número de sílabas del verso entre las dos y las catorce «mas no todos los acepta el oído con el mismo gusto y placer»; así, considera pésimos los de nueve y los de trece sílabas, «de cualquier modo que se construyan», y lo mismo ocurre con los de quince y diecisiete sílabas de que habla 
Luzán, «y los de diez y seis y cualquiera otros que V. quiera agregar a ésos». Sólo si cambia la índole de nuestra prosodia podrán inventarse nuevos metros «que nuestros ultra-retataranietos acepten»; es mejor, pues, templar bien los versos que hay. El caso de Sinibaldo de Mas, «paladín el más esforzado de un nuevo método de versificar», sirve de ejemplo para aparcar cualquier intento de revolución, pues sus dodecasílabos, tridecasílabos y pentadecasílabos no constituyen un modelo para seguir. Más aceptables considera sus ejemplos de hexámetros (Miguel Agustín Príncipe, 1861-2: 390, 636-8).

Sinibaldo de Mas y Miguel Agustín Príncipe significarían la posibilidad de dos actitudes teóricas diferentes ante la cuestión del canon: apertura y experimentación, por un lado; conservadurismo y sometimiento a la costumbre por otro. ${ }^{18}$ En cualquier caso, lo que está claro es que hay un ambiente de discusión, síntoma de que algo está pasando y de que algo tiene que pasar con la forma del verso.

Las comparaciones de la lista de versos descritos en manuales de fechas distintas de este período nos proporcionarían muchos ejemplos de cambios en el canon. Pero, por dar sólo una muestra de cuál es la situación una vez que el modernismo ha triunfado, léase la lista de tipos de versos que registra Max Henríquez Ureña en sus Estudios de versificación (1913):

18 En nuestro mencionado trabajo sobre teorías métricas de los siglos xVIII y xIX pueden verse otros ejemplos de esta discusión (1975: 222-233). Así, José Manuel Marroquín, en sus Lecciones de métrica (1875), expone también la tesis de que la costumbre es la que hace que un determinado número de sílabas sea acogido como nueva especie de verso. En castellano sólo hay siete clases de versos: de cinco, seis, siete, ocho, nueve, diez y once sílabas, pues los de doce y los de catorce no son más que la unión de dos de seis y dos de siete, respectivamente. Pero no puede negar que el uso ya en su misma época acepta más especies de verso, que sólo admitirá «si la generalidad de los que hablan castellano llega a conocerlas y distinguirlas». Que está pensando incluso en versos usados por poetas de primera nota, lo dice explícitamente Marroquín, pero lo justifica porque el poeta es empujado por el pensamiento y no quiere sacrificarlo a la forma, lo que le lleva a adoptar una impropia (J. Domínguez Caparrós, 1975: 228-9). Léase allí, también (págs. 224-225), la opinión de Vicente Salvá (1859), que no cierra la puerta a versos de 16 y 18 sílabas. 
Versos simples (los que se componen de los distintos tipos de cláusulas bisílabas, trisílabas y tetrasílaba):

pentasílabo (yámbico, dactílico)

hexasílabo (trocaico, anfibráquico)

heptasílabo (yámbico, anapéstico)

octosílabo (trocaico, dactílico)

eneasílabo (yámbico, anfibráquico)

decasílabo (trocaico, anapéstico)

endecasílabo (yámbico, dactílico)

dodecasílabo (anfibráquico, trocaico)

tridecasílabo (yámbico, anapéstico)

alejandrino francés (mezcla de simples y compuestos)

Versos compuestos (formas más usadas, de las 40 ó 50 posibilidades teóricas):

$$
\begin{aligned}
& \text { octosílabo }(3+5) \\
& \text { eneasílabo }(3 \text { anfibráquico }+6 \text { troqueo; } 4+5) \\
& \text { decasílabo }(5+5 ; 3+7 ; 7+3 ; 6+4 ; 4+6) \\
& \text { endecasilabo }(6+5 ; 4+7) \\
& \text { dodecasílabo }(6+6 ; 7+5 ; 5+7) \\
& \text { tridecasílabo }(5+8 ; 7+6 ; 6+7 ; 8+5) \\
& \text { alejandrino (castellano: } 7+7 ; \text { francés: } 8+6 ; 9+5 ; 10+4 \text {; } \\
& \quad \text { o viceversa) } \\
& \text { pentadecasílabo }(6+9 ; 5+5+5) \\
& \text { hexadecasílabo }(8+8 ; 10+6 ; 6+10 ; 7+9) \\
& \text { heptadecasílabo }(7+10 ; 7+5+5 ; 9+8) \\
& \text { octodecasílabo }(9+9 ; 6+6+6 ; 11+7 ; 7+11 ; 5+5+8) \\
& \text { eneadecasílabo }(5+5+9 ; 10+9) \\
& \text { veinte sílabas }(10+10 ; 5+5+5+5)
\end{aligned}
$$

Estas 61 especies de verso, todas atestiguadas con ejemplos, no agotan las posibilidades, pues hay que añadir el verso libre y las adaptaciones de hexámetros, como nos señala el mismo Max Henríquez. El verso moderno cuenta, así, con posibilidades insospechadas al principio de sus tanteos dieciochescos.

Una idea del ambiente de curiosidad respecto a las formas métricas, nos la da el llamamiento de la nota con que termina su trabajo Max Henríquez (1913: 124): 
Agradeceré a cuantas personas tengan interés en esta clase de estudios, la remisión de los datos que posean sobre el uso de metros nuevos y combinaciones rítmicas, para tenerlos en cuenta en trabajos que me propongo llevar a cabo.

El canon está vivo y depende del uso innovador. ${ }^{19}$ Compárese con las listas cerradas de tiempos anteriores. ${ }^{\mathbf{2 0}}$

\section{4}

Una última cuestión teórica que quisiera apuntar en relación con la forma en que hay que entender la construcción del verso moderno es la del silabotonismo. Dice M. L. Gasparov (1996: 269) que en la segunda mitad del siglo xix es cuando la versificación silabotónica alcanza su apogeo en las literaturas europeas (inglesa, alemana y rusa). Sorprendentemente, este apogeo coincide temporalmente con los ensayos premodernistas y modernistas de versificación de cláusulas, de que da testimonio la polémica entre Eduardo de la Barra y Eduardo Benot. Pero estos

19

Esto no significa que no haya muestras anteriores de la vitalidad del canon. Coll y Vehí, por ejemplo, dice del eneasílabo, en sus Elementos de arte métrica latina y castellana (1854: 29), que apenas se pueden citar otros más que los de Iriarte, en su fábula El manguito, el abanico y el quitasol. En sus Diálogos Literarios (1866), sin embargo, se refiere a los de Espronceda (acentuados en 2, 5 y 8: Y luego el estrépito crece), que ya le parecen «otro cantar», y en los que las sílabas «están agrupadas de tres en tres, puesto que constantemente tienen acentuadas la segunda y quinta». Este mismo tipo de eneasílabo es registrado por Coll y Vehí en Zorrilla (Leyenda de Alhamar) y en la Avellaneda (La pesca en la mar, La Cruz) (Coll y Vehí, 1866: 314-5). Curiosamente el eneasílabo esproncedaico está registrado como posibilidad teórica en Masdeu (1801: 71-72), que da los siguientes ejemplos: saliendo del puerto la nave; balando la tímida oveja.

Por ejemplo, con la que propone Alberto Lista (1840): «Tres son los metros más comunes en nuestra poesía: el verso de once sílabas, el de siete y el de ocho» (1840: 5). Respecto al alejandrino de Berceo, dice. «Trigueros y algunos poetas peores que él, solicitaron restablecerlo a fines del siglo pasado, empresa para la cual no bastaría el genio de Herrera» (1840: 9). Además de los versos de 4 sílabas, que son los más cortos, los hay de 6, 7, 8, 9, 10 y 11: «Más allá no hay metros; pues el de 12 se compone necesariamente de dos de 6 , y el de 14 de dos de 7 . Nadie, que nosotros sepamos, ha usado ni aun examinado el de 13. Parece que este es el término desde el cual en adelante no puede ya el oído percibir la medición del verso» (1840: 10). 
ensayos de versificación de cláusulas no hacen más que culminar un proceso de invención de nuevos metros silabotónicos, es decir, de versos con lugar muy fijo del acento interior, en el neoclasicismo y en el romanticismo.

Proceso que como ya sabemos está bien testimoniado por los teóricos de la métrica que destacan en el análisis de la estructura interna del verso como Masdeu, Sinibaldo de Mas, Bello, y Príncipe. Sitúa Gasparov (1996: 270-273) el ímpetu inicial del silabotonismo de las métricas románicas en la primera mitad del siglo XVIII, en Italia, en estrecha relación con la música. El libretista Pietro Metastasio cultiva un heptasílabo con ritmo yámbico (acento en las sílabas pares) y un octosílabo de ritmo trocaico (acento en las sílabas impares). Por influencia francesa, además, empiezan a utilizarse, tanto en italiano como en español, el alejandrino y el eneasílabo, pero lo hacen con un esquema rítmico mucho más estricto que su modelo francés. El alejandrino se hace un hexámetro yámbico (seis grupos de dos sílabas con acento en la segunda), y el eneasílabo adopta las formas de un tetrámetro yámbico o un trímetro anfibráquico (acentos en $2^{\mathrm{a}}, 5^{\mathrm{a}}$ y $8^{\mathrm{a}}$ ). Además de alejandrino y eneasílabo, cita Gasparov, en lo que se refiere a España, el verso de arte mayor, regularizado en dodecasílabo con la forma de tetrámetro anfibráquico. A los versos nuevos y a los restaurados, hay que añadir los experimentos para silabotonizar las formas más tradicionales.

No resulta difícil ilustrar estas tendencias anotadas por Gasparov. Bello, por ejemplo, habla en el alejandrino de manifiesto "predominio del ritmo yámbico». Masdeu ya registra el eneasílabo anfibráquico; Bello y Salvá, el yámbico. Y estos dos últimos autores, el ritmo anfibráquico del verso de arte mayor. Ejemplos de silabotonización de todos los tipos de versos se encuentran en las formas de versos registradas en cualquier página del diccionario final de mi trabajo sobre la teoría métrica de este período (1975).

Sólo quiero mencionar el análisis que hace José Coll y Vehí (1866: 295-298) de los versos del poema de Gertrudis Gómez de Avellaneda, La noche de insomnio y el alba, donde dodecasílabos 
y decasílabos, por ejemplo, están perfectamente vistos como versos silabotónicos de ritmo ternario. Sin olvidar la referencia histórica al uso de su tiempo:

Espronceda, Zorrilla, y muchos otros reputados poetas de nuestros tiempos, han resucitado los versos alejandrinos, de arte mayor y decasílabos [...].

Y un verso tan característicamente silábico como el octosílabo no deja de ser analizado también en su estructura acentual. Así, son más enérgicos y frecuentes con acento en tercera (1866: 316-318).

Pero no hay que insistir en algo que se impone en el primer contacto con la teoría y la práctica del verso moderno: la minuciosa atención a la repartición de acentos en el interior. Esto es muestra de una conciencia silabotónica que además coincide con las tendencias generales de la versificación europea. Así se carga de más sentido la afirmación de Bello cuando dice, en el prólogo de la primera edición de su Ortología y métrica (1835), que la versificación castellana, bajo el aspecto de sus «verdaderos principios o elementos constitutivos del metro... tiene grande afinidad con las de casi todas las naciones cultas modernas» (1981: 7).

Sentido histórico, con su consiguiente relativismo, análisis detenido de las estructuras internas de acentos y pausas, fundados en principios silabotónicos, tienen como resultado la abundancia de formas ensayadas, a veces con vocación experimental de base para propuestas de futuro. Es en el modernismo cuando tales propuestas alcanzan su nivel de consagración, para unas, o de meros ensayos que se desechan casi del todo, para otras, como es el caso de la versificación de cláusulas. 


\section{REFERENCIAS BIBLIOGRÁFICAS}

ALONSO, D. (1952): Poetas españoles contemporáneos, en Obras completas, Madrid, Gredos, 1975, t. IV.

BARRA, E. de la (1891): Nuevos estudios críticos sobre versificación castellana, Santiago de Chile, Imprenta Cervantes.

BELLO, A. (1835): Principios de la Ortología y Métrica de la lengua castellana, en Obras Completas, VI, Caracas, La Casa de Bello, 1981.

BOTI, R. E. (1921): "Dilucidaciones métricas”, en Cuba Contemporánea, XXVI, págs. 332-369.

CLARKE, D. C. (1952): “On Iriarte’s versification”, en PMLA, LXVIII, págs. 411-419.

COLL Y VEHÍ, J. (1854):Elementos de arte métrica latina y castellana, Madrid, Rivadeneyra.

- (1856) Elementos de literatura, Madrid, Rivadeneyra, 1857, $2^{\text {a }}$ ed. corregida.

- (1866) Diálogos literarios, Barcelona, Juan Bastinos, 1871, $2^{\mathrm{a}}$ ed.

DOMÍNGUEZ CAPARRÓS, J. (1975): Contribución a la historia de las teorías métricas en los siglos XVII y XIX, Madrid, C.S.I.C.

- (2002) Métrica de Cervantes, Alcalá, Centro de Estudios Cervantinos.

DREPS, J. A. (1939): “Was José de Espronceda an innovator in metrics?”, en Philological Quarterly, XVIII, I, págs. 35-51.

GASPAROV, M. L. (1996): A history of european versification, translated by G. S. Smith and Marina Tarlinskaja, Oxford, Clarendon Press.

GONZÁLEZ, J. G. (1844): Obras en verso y prosa, Madrid, Imprenta de Alegría y Charlain, 3 vols.

HENRIQUEZ UREÑA, M. (1913): “Estudios de versificación”, en Cuba Contemporánea, III, págs. 89-124.

HENRÍQUEZ UREÑA, P. (1905): “Rubén Darío”, en Ensayos, edición crítica coordinada por José Luis Abellán y Ana María Barrenechea, Madrid, ALLCA XX (Colección Archivos, 35), 2000, 2ª ed., págs. 209-221.

- (1961): Estudios de versificación española, Buenos Aires, Universidad de Buenos Aires.

IRIARTE, T. de (1963): Poesías. Prólogo y notas de Alberto Navarro González. Madrid, ESpasa-Calpe (Clásicos Castellanos, 136).

JAIMES FREYRE, R. (1912): Leyes de la versificación castellana, México, Aguilar, 1974.

LISTA, A. (1840): “De la versificación castellana”, en Ensayos literarios y críticos, II, Sevilla, Calvo-Rubio, 1844, págs. 5-11.

LUZÁN, I. de (1977): La Poética. Primera edición completa de ambos textos dieciochescos (1737 y 1789), edición de Russell P. Sebold, Barcelona, Labor. 
MAS, S. de (1832): Sistema musical de la lengua castellana, edic. de José Domínguez Caparrós, Madrid, C.S.I.C., 2001.

MASDEU, J, F. de (1801): Arte poética fácil, Valencia, Burguete.

MAURY, J. M. (1826-27): Espagne poétique, Paris, Mongie, 2 v.

NAVARRO TOMÁS, Tomás (1956): Métrica española. Reseña Histórica y descriptiva, Madrid, Guadarrama, 1972, $3^{\text {a }}$ ed. - (1973)Los poetas en sus versos, Barcelona, Ariel, 1982.

PÉREZ Y CURIS, M. (1913): Arquitectura del verso, Paris, México, Librería de la Vda. de C. Bouret.

PRÍNCIPE, M. A. (1861-62): Fábulas en verso castellano y variedad de metros, Madrid, Ibo Alfaro.

RENGIFO (Juan Díaz Rengifo) (1606) Arte poética española, edición facsímil, Madrid, Ministerio de Educación y Ciencia, 1977.

- (1759) Arte poética española, aumentada por J. Vicens, Barcelona, María Ángela Martí, s. a. [1759].

VICUÑA CIFUENTES, J. (1929) Estudios de métrica española, Santiago de Chile, Editorial Nascimento. 